and subgeneric names recorded in the volume, comprising the rather surprisingly high number of 1,602 new names. Whereas Insecta again heads the list with 836, more than half the total, here the position of Aves is reversed, as it is near the bottom of the list with only seven new names. The last new generic name is the enigmatical word $Z y x$, which seems bound to remain at the bottom of any alphabetical list.

It is rather unfortunate that the literature relating to Vermes for 1952 and to Trilobita for 1953 is not yet available, but it is hoped to publish these sections in a later volume. However, this is only a minor defect, and zoologists throughout the world owe a great debt to all those who have helped to compile this invaluable publication.

EDWARD HINDLE

\section{PLASTIC METHODS OF STRUCTURAL ANALYSIS}

The Plastic Methods of Structural Analysis By Prof. B. G. Neal. Pp. xi+353. (London : Chapman and Hall, Ltd., 1956.) 45s. net.

DROF. B. G. NEAL'S name is well known to those who have followed the development of the 'plastic method' of design and analysis. He has been one of the famous Cambridge team, and a book from his pen on this subject is welcome. The text is pleasant and readable in lay-out-an important virtue -and the author resists the temptation to which so many writers on structures fall a victim: that of going back to the beginning, and laboriously taking the reader, once again, through the elementary principles. Prof. Neal plunges straight into his subject, and writes in a style which is crisp and to the point. He avoids the disease of the singlesentence paragraph which afflicts much writing on technology to-day.

The book, although eminently readable and particularly suitable for the library of the senior student of civil engineering, is nevertheless a serious and critical survey of this approach to the analysis and design of statically indeterminate structures. The plastic method is certain, in the end, to displace elastic analysis; but, judging by the fate of some new ideas in engineering, the period of gestation may well be long. It is particularly valuable, therefore, to find, in the first four chapters, a succinct survey of basic theorems and general methods of plastic design. The professional engineer, as well as the undergraduate, can well understand the procedures described-so much simpler than the complex analyses for elastic frames of high redundancy.

The final four chapters deal with deflexion, minimum-weight design and repeated loading, and with the factors which affect the value of the fully plastic moment. The student of the subject can well expect, from these chapters, to be led to understand the latest developments. The difficult problems presented by multi-story, multi-bay frames could well have been elaborated, and the excellent index does not contain the word 'joint'. Yet the design of the joints in a redundant structure is of vital significance if the structure is to behave as postulated and not to show premature collapse by reason of shear failure of the joints themselves.

Two of the attractive features of the book occur at the end of each chapter, where the comprehensive lists of references will delight the serious student of the subject. The numerous numerical exercises will, similarly, attract the student working for examinations. The contents of the book represent the distilled experience of one of the engineers who have developed this British method of analysis and design, and the matter is the stuff of the future. It cannot be neglected by the young engineer, who is fortunate in having at his disposal such a clear and readable exposition.

W. F. Cassie:

\section{PROGRESS IN CHEMICAL ENGINEERING}

Advances in Chemical Engineering

Edited by Thomas B. Drew and John W. Hoopes, Jr. Vol, 1. Pp. $x+448$. (New York: Academic Press, Inc.; London: Academic Books, Ltd., 1956.) 10 dollars; $80 \mathrm{~s}$.

HIS is the first of a series of volumes giving up-to-date critical summaries of work in fields of chemical engineering where advances have been rapid in the past few years. Although some of the topics are of wide interest, others will appeal only to small groups and could probably have been better covered by a series of monographs. The individual contributors are all experts in their particular fields, but in some cases do not show the familiarity one would expect with work carried out in Great Britain and elsewhere in Europe.

The first chapter, on the boiling of liquids, begins with a comprehensive account of the phenomena associated with boiling on a submerged surface, and the differences between nucleate, transitional and film boiling are clearly illustrated by a series of photographs. Theoretical and empirical relationships for heat transfer under nucleate conditions are discussed and a detailed theoretical treatment of the nucleation process is given. Many of the expressions are, how ever, difficult to apply because a number of the factors which determine the nature of the surface defy quantitative definition. The chapter would have been strengthened by a discussion of boiling in long tube evaporators, and of heat transfer at very low temperatures to materials such as liquid air.

The classification and a general summary of the properties of non-Newtonian fluids form a valuable introduction to the second chapter, which then continues with an account of the methods of calculating the pressure drop arising from the flow of a suspension in a pipe. Reference is made to the phenomenon noted by a number of workers-that the pressure drop for the flow of a suspension is sometimes less than that for the flow of the liquid alone. Possible explanations are given, first in terms of slip at the walls of the tube, and secondly by considering the difference in the structure of turbulence in a homogeneous fluid and a suspension. Among other features referred to are the problems of mixing and heat transfer to suspensions, and the chapter concludes with a description of some of the methods of measuring physical properties.

The theory of diffusion is treated in the following chapter at a level which will be beyond most practising chemical engineers. Relations are given for mass transfer in flowing systems for both binary and 